Appendix A: Questionnaire

\title{
Question 1:
}

Age.

Question 2:

Gender.

Question 3:

Occupation

Question 4: Atheism is the absence of religion. *

Question 5: Atheism is more than the absence of religion. *

Question 6: Science influenced my decision to be an atheist.*

Question 7: I sometimes have doubts about my atheism. *

Question 8: Are/were one or both of your parents' atheists?

Question 9: Humanists should bring up their children as atheists. ${ }^{*}$

Question 10: Humanists should allow their children to make their own decision on atheism.*

Question 11: There is some absolute meaning in the universe.*

Question 12: If you believe that there is some absolute meaning in the universe, please briefly state what you think it is.

Question 13: Briefly state who or what influences your moral decisions.

Question 14: I agree with the New Atheists such as Richard Dawkins that one should actively attack religion. *

Question 15: I believe that religion is evil.*

Question 16: One can be spiritual without being religious.*

Question 17: Have you ever had an extra worldly experience? If so, please briefly describe it.

Question 18: All religion is superstition.*

Question 19: Humanism is conducive to mental health.*

Question 20: Humanism and Atheism are the same thing.*

${ }^{*}$ Questions marked with an asterisk had the following response options: strongly

agree, agree, neutral, disagree, and strongly disagree

For questions 4-21 respondents were asked to provide verbatim statements to expand upon their Likert response. 